\title{
Attenders or attendees? Deverbal -ee and -er variants in English
}

\author{
Liesbet Heyvaert* \\ K.U. Leuven, Campus Kortrijk, Department of Linguistics, Etienne Sabbelaan 53, 8500 Kortrijk, Belgium
}

\section{A R T I C L E I N F O}

\section{Article history:}

Received 13 November 2009

Received in revised form 12 July 2010

Accepted 10 August 2010

\section{Keywords:}

Nominalization

Derivation

English

er nouns

ee nouns

\begin{abstract}
A B S T R A C T
This paper presents a qualitative corpus analysis of deverbal -ee and -er pairs with agentive, human reference (e.g. escaper-escapee; attender-attendee) as they occur in natural discourse. It is argued that pairs like these are not synonymous or idiosyncratic formations, but represent systematic instantiations of their respective systems of nominalization whose distinct meanings can be traced back to that of the overall system which they belong to: the -er nouns typically foreground the active, dynamic perspective of -er derivation, focusing on the agent's ability, potential or intention to carry out an action, or on the regularity with which it is carried out; their counterparts in -ee, on the other hand, zoom in on the state that the agents find themselves in as a result of performing a certain process.
\end{abstract}

(c) 2010 Elsevier B.V. All rights reserved.

\section{Introduction}

Deverbal nominalizations in -ee and -er are often bracketed together. Synchronically speaking, they are the two most productive participant-profiling systems of nominalization in English. -ee nominalizations were first derived in the 15th century to serve as non-agentive counterparts of -er nouns in legal texts (Jespersen, 1914-1929, part VI; Marchand, 1969; Kastovsky, 1986). And both systems have undergone processes of extension which have brought their originally complementary profiles significantly closer together. In particular, the original, agentive (esp. human) profile of deverbal -er nominalization (see (1a)) has been complemented with inanimate, non-agentive formations (as in (1b)), whereas the prototypically human, non-agentive system of -ee derivation ((2a)) has expanded to include agentive entities (as in (2b)).

a. $\quad$ writere 'writer'; bcekere 'baker'; leornere 'learner'; rcedere 'reader' (Kastovsky, 1971)

b. broiler 'young chicken suitable for broiling'; kneeler 'a kind of chair'; squeezer 'a kind of container that you have to squeeze in order to extract something from it'

a. payee, adoptee, employee, detainee

b. escapee, resignee, returnee, attendee

As a result of these extensions, a kind of 'grey area' has come to exist between -ee and -er derivations-not so much between their non-agentive instantiations (among other things, because non-agentive -er nouns are overwhelmingly inanimate, whereas their non-agentive counterparts in -ee are always human in profile), ${ }^{1}$ but rather between their agentive subtypes. There are, more particularly, agentive contexts in which both an -er nominal and its -ee variant are possible ${ }^{2}$ :

\footnotetext{
* Corresponding author. Tel.: +32 163248 09; fax: +32 16324767 .

E-mail address: liesbet.heyvaert@arts.kuleuven.be.

1 Some examples of non-agentive -er nouns with human reference can be found, e.g. looker 'a good-looking person' and keeper 'something or someone worth keeping'.

${ }_{2}$ The examples followed by $(\mathrm{CB})$ were all extracted from the COBUILD Corpus and are reproduced here with the kind permission of HarperCollins.
} 
a. Prison escaper John Hannan has set a British record by staying on the run for 42 years. (CB)

b. A mother held hostage by an armed prison escapee in an ordeal has been hailed as a heroine by Sydney police. (CB)

The semantic differences between both variants have tended to be minimized. In Booij and Lieber (2004:344), for instance, it is argued that while "the basic semantic contribution of the two affixes is exactly the same", "-er places no semantic restrictions on its co-indexed argument, but -ee does place such requirements. Specifically, it places a STRICT requirement of sentience on its coindexed argument and a WEAK requirement (...) of nonvolitionality". Applied to escapee and escaper, this analysis suggests that escapee differs from escaper in that it is non-volitional (both nominals designating a sentient entity). However, 'lack of volition', first proposed by Barker (1998) as one of the unifying features behind the system of -ee derivation, seems unable to capture the semantics of escapee: to argue that someone who is an escapee did not want to escape somehow conflicts with the language user's understanding of this word. Barker (1998:719) points out himself that an escapee "typically is volitionally, actively, and deliberately involved in bringing about the escaping event". Indeed, the use of the notion of "lack of volition' to account for the agentive type of -ee derivation in general is, as Barker (1998:719) himself admits, "less than fully compelling". The distinction between escapee and escaper thus remains unaccounted for.

Do we have to conclude from this that -ee and -er pairs are semantically identical and that their co-existence is incidental? This is at first sight what Barker (1998:709) seems to suggest when he states that "there are a number of cases in which a single verb has given rise to both an -ee form and an -er form that are essentially synonymous - i.e. have the same set of individuals in their extension". Yet, in his discussion of the pair escapee - escaper he points to the various distinct meanings which they have: while escapee "has come to be nearly synonymous with fugitive" (Barker, 1998:719), "escaper is the name of a model of recreational vehicle; independently, escaper is also used as a derogatory epithet for players on the internet go server who deliberately pretend to lose their net connection in order to avoid losing a game of go" (Barker, 1998:709). While Barker thus recognizes semantic differences between the -ee and -er variant of escape, he also seems to suggest that they are due to incidental semantic specialization.

The tendency to either minimize semantic differences or analyze them as idiosyncratic and non-systematic is not unique to the analysis of the -ee and -er variants of one verbal lexical item. Comparable claims have been made about various extensions of -ee and -er nominalization in general. Agentive -ee nouns, for instance, have been discarded as anomalous and it has been argued that "somehow an extra limitation must be built into the grammar to show that this process of word-formation is not a preferred method of forming derivatives" (Bauer, 1983:247). Similarly, English as well as Dutch non-agentive -er nominalizations have been analyzed as non-systematic in nature (Keyser and Roeper, 1984; for Dutch: Booij, 1986; Taeldeman, 1990). Against this, I have argued that a unified analysis, which includes non-agentive -er and agentive -ee nominalizations and integrates the latter's formal and semantic properties into an overall account of -er and -ee derivation, is possible-for-er nominalization (Heyvaert, 2003) as well as for -ee derivation (Heyvaert, 2006). In this paper, I want to zoom in on the grey area of -ee and -er pairs with agentive, human reference, such as escaper-escapee and attender-attendee. In particular, I will show that careful qualitative analysis of actual empirical examples of such pairs largely confirms the in-depth semantic analysis of -er and -ee derivation presented in Heyvaert $(2003,2006)$ : a majority of the agentive -er nouns and their -ee alternatives turn out to be systematic instantiations of their respective systems of nominalization with distinct meanings that can be traced back to that of the overall system which they belong to (of -er and -ee derivation).

Because it is essential to have an understanding of the semantic and formal properties of the systems of -er and -ee nominalization in general, I will in section 2 briefly summarize the general analyses proposed in Heyvaert (2003) for -er nominalization and in Heyvaert (2006) for -ee derivation. Section 3 then presents the results of the corpus analysis which I carried out of a number of -ee and -er pairs. Some concluding remarks are formulated in section 4.

\section{The systems of -er and -ee nominalization}

The literature on -er and -ee nominalization has long polarized into a syntactic versus a semantic approach. In the syntactic approach to -er nominalization, it is suggested that all -er nominalizations designate the 'external argument' or the "underlying (D-structure) subject" of their base verb (Levin and Rappaport, 1988:1074; see also Rappaport Hovav and Levin, 1992). In the syntactic perspective on -ee nominalizations (first formulated in Bengtsson, 1927), the unifying feature behind the system of -ee derivation is held to be "the ability of all the nouns to appear as subjects of verbs with passive forms" (Bauer, 1983:246). Neither of these syntactic accounts, however, succeeds in offering a satisfactory account of the less prototypical -ee and -er nominalizations: non-agentive cases of -er nominalization like the ones in (1b), which profile an internal argument or the 'underlying (D-structure) object' of the base verb, are problematic to Levin and Rappaport's 'external argument generalization'; agentive -ee nouns like the ones in (2b) cannot be analyzed as subjects of passive clauses.

Due to the failure of the syntactic approaches to give a unifying account of -er and -ee derivation, the pendulum has swung in favour of a purely semantic approach. In Ryder $(1991,1999)$ it is argued that all non-agentive -er nominalizations are reanalyses of the agentive prototype, reanalysis being possible when a non-agentive entity is conceived as being agent-like and salient or particularly noticeable within the designated event. The agentive cases of -ee nominalization, then again, have been argued to share a certain degree of 'lack of volition' (Barker, 1998; Booij and Lieber, 2004) or 'undergoerhood' (Portero Muñoz, 2003) with their non-agentive counterparts in -ee. In addition, like non-agentive -ee nouns, they are said to be 
'episodically linked', i.e. "the referent of the noun phrase headed by an -ee noun must have participated in an event of the type corresponding to the stem verb" (Barker, 1998:711).

Unfortunately, the semantic analyses of -ee and -er nominalization tend to make use of rather vague concepts which are not always intuitively plausible when applied to the non-prototypical cases of -ee and -er. The notion of 'agent-like salience' which Ryder proposes to account for non-agentive -er nouns, for instance, conflicts with the language user's interpretation of, among others, non-agentive items such as broiler 'a chicken fit for broiling' and cooker 'an apple for cooking', and the suggestion that "the food that is cooking, at least in modern kitchens, is often the most prominent participant actually present in the event" (1999:289) fails to convince. The claim that the agentive nouns in -ee are somehow characterized by a lack of volition or control, either "over the direct consequences of the event" or over "the circumstances that led the person to escape, to resign, to retire” (Barker, 1998:719) is not compelling either. Finally, Barker's notion of 'episodic linking', while basically correct (and undeservedly dismissed as 'commonplace' in Portero Muñoz (2003:132)), is rather fuzzy.

Rather than opting for a purely syntactic or semantic approach to nominalization, the alternative analyses proposed in Heyvaert $(2003,2006)$ focus on the symbolic status of the relationship created through -er and -ee derivation, i.e. they zoom in on the constructional link which these nominalization systems establish between a profiled entity and a verb and identify the semantics that is (symbolically) encoded by that link. The system of -er nominalization, it is argued in Heyvaert (2003), systematically relates to the Subject-Finite unit at clause level, its basic semantics mirroring the various modal and temporal relationships that can be expressed within that unit: lexicalized -er nominalizations turn out to typically express modal meanings, whereas the so-called 'ad hoc' type, which is derived 'on the spot' to serve a specific discourse need (e.g. (4)), tends to express non-modal, temporal meanings:

a. Recent research has established that merely breathing smoke-laden air - passive or 'second-hand' smoking - puts the breather at risk. (CB) [the one that breathes]

b. One guy jumped right into the fight, but his friend immediately vanished. The police came and hauled off the fighter, after which the vanisher promptly reappeared, laughing. (Ryder, 1999:283) [the one that had been fighting; the one that had vanished]

The oldest, human agentive type of -er nominalization (e.g. baker, fisher, engraver, wood-cutter) instantiates types of modality which come close to the historical antecedent of the English modal can, which indicated that "its subject had the knowledge or mental ability to do something" and that of may, which specified that the subject had "the necessary strength or physical ability" (Langacker, 1991:269). Many Modern English agentive nominalizations in -er still assign some degree of ability to the agent which they profile: a lifesaver is someone who knows how to save lives; a fire-fighter knows how to fight a fire; a warbler can warble or sing pleasantly; a transmitter can transmit television or radio programmes. In addition, many lexicalized agentive -er nominalizations imply that the profiled agent carries out the process regularly, habitually or professionally: a baker is someone who knows how to bake bread and will typically bake bread regularly, professionally. Agentive -er nominalizations thus tend to designate characteristic or habitual behaviour. Nominalizations like drinker, gambler, wood-pecker even characterize their profiled agents in terms of a persistent habit. $^{3}$

How do the non-agentive types of -er nominalization (which are all lexicalized) fit into this modal account? Following up on a suggestion first made in Levin and Rappaport (1988) and Lemmens (1998), I have argued in Heyvaert (2003) that nonagentive -er nominalizations can be systematically related to the Subject-Finite unit of clausal middle constructions.

$$
\begin{aligned}
& \text { broiler 'a chicken that broils well' } \\
& \text { bestseller 'a book that sells well' } \\
& \text { easy-rider 'a motorbike that rides easily' }
\end{aligned}
$$

More particularly, I have pointed out that, like middle clauses, non-agentive -er nominalizations establish a relationship that is basically modal in nature and profiles an entity's conduciveness towards a specific process ${ }^{4}$ : a kneeler is thus conducive to kneeling, i.e. it enables you to kneel on it; a sleeper is a train that has beds that let you sleep; a walker is a frame that makes it possible to walk, it lets one walk. Importantly, as in the middle construction, the properties of the profiled entity have typically been designed or intended for a particular process (Lemmens, 1998:138). Like middles, moreover, non-agentive -er nominals can profile various facets of the designated event: they can zero in on how (well/easily) the properties of the profiled entity let the process be carried out (e.g. bestseller, easy-rider, easy-walker), they can profile where the properties of the profiled entity allow the process to be carried out (e.g. front-loader, top-loader, low-loader), or they can simply express that the properties of the profiled entity make a particular process feasible: a stroller, for instance, allows you to take your baby out and stroll (comfortably) with it; a walker is a frame which helps babies or disabled or ill people to walk (more easily). In my view, also Barker's (1998:709) first example of escaper as 'the name of a model of recreational vehicle' belongs with this

\footnotetext{
${ }^{3}$ The various modal meanings that nouns in -er can carry are nicely illustrated in a slogan which the Belgian government recently used to convince smokers to quit smoking: in elke roker zit een stopper 'every smoker hides a stopper'. While roker 'smoker' carries the modal meaning of persistent habit (implying regularity), stopper 'stopper' exploits the semantics of potentiality that is associated with modality ('someone with the potential to stop, i.e. quit smoking').

4 See Heyvaert (2003) and Davidse and Heyvaert (2007) for a more elaborate account of the modal status of middle constructions.
} 
non-agentive category and designates a vehicle which lets you escape, which enables you to feel 'free' and/or 'get away from difficulties or problems'. Non-agentive -er nominalizations denoting items of food, finally, resemble the so-called 'resultoriented' type of middle construction (Heyvaert, 1997):

She does not photograph well (...) (CB)

[about a piece of clothing:] It washed well with little shrinkage and no puckering. (CB)

The middle constructions in (6) and (7) do not have the prototypical, facility-oriented meaning of middles with well: they do not signal that the person in (6) is difficult to photograph or that the piece of clothing in (7) washes easily (as in this car drives well; see also Fellbaum, 1986:10). Rather, they emphasize that the results of photographing her ((6)) and of washing the piece of clothing ((7)) are (not) good: the pictures taken of her are hardly ever beautiful, the piece of clothing referred to does not shrink or show signs of puckering. Similarly, non-agentive -er nominals designating items of food tend to focus on the result of preparing it in a certain way and thus hint at how to prepare the food to achieve the most delicious or best possible result:

$$
\begin{aligned}
& \text { broiler 'this type of chicken broils well' } \\
& \text { cooker 'this type of apple cooks well' } \\
& \text { fryer 'this type of chicken/rabbit fries well' }
\end{aligned}
$$

In short, by positing a relationship of equivalence between non-agentive -er nominalizations and the Subject-Finite unit in middle formation, the non-agentive cases of -er derivation can be accounted for and identified as full members of the system of deverbal -er nominalization. The central generalization behind the system then is that the constructional link which it establishes between an entity and a process resembles that between a subject and a finite at clause level. While in agentive -er nominals the profiled subject-like entity is also the 'doer' of the process, non-agentives have the added meaning associated with the subject in middle constructions and profile the conduciveness of the subject towards a specific process. Instrumental -er nominals (like peeler, grater, poker, knocker) hover between being able to carry out the process itself (as agent-like subjects; e.g. This peeler peels fruit and vegetables quickly; but ?this poker pokes the wood in the fire) and enabling others to carry out the process (like non-agentives; e.g. This poker enables you to poke the wood in the fire).

In the symbolic approach to derivation in -ee set out in Heyvaert (2006), it is argued that the key to a better understanding of the system lies in its origins as anglicized version of the French past participle. More particularly, it is suggested that the various extensions found within the system of -ee nominalization mirror the network of related meanings realized by the English past-participial morpheme in a number of constructions, adjectival (as in (9)) as well as clausal ((10)).

a. For our best selling matured cheddar we go to both Cornwall and Scotland. (CB)

b. After calling for an inside ball he copped a shocker of an inside pass, leaving him with a cracked rib. (CB)

a. People were tortured in the cellar. (CB)

b. The delay has fuelled suspicions of ill health and internal power struggles. (CB)

The examples in (9) illustrate the so-called 'stative' or 'adjectival' use of the past participle and restrict the profile to "the final, resultant state of the process" (Langacker, 1991:202), resulting from a participant "undergoing a change" (1991:203). They differ in that (9a) is based on a one-participant or intransitive verb (mature), while cracked in (9b) clearly implies two participants and profiles the 'done to' or the patient of the process. The past participle in (10a) illustrates the prototypical, passive use of the participle, whereas in (10b) a past participle figuring in the present perfect is given.

As described in Langacker $(1982,1991)$, all these uses of the past participle in one way or another seem to enhance the salience of a 'downstream' or 'terminal' element: its adjectival uses restrict the profile to a single state that results from a participant undergoing an internal change (with intransitives) or a change effected by some other entity (with transitives). The adjectival uses of the past participle are therefore analyzable as 'downstream' with respect to the flow of time (Langacker, 1991:203), and, in the case of a transitive base verb, they are also 'downstream' with respect to the flow of energy (profiling a non-agentive entity). The clausal uses of the past participle, then, profile either a participant which itself is 'passive' or downstream with respect to the flow of energy (the passive use of the past participle); or, in the perfect use of the participle, a temporal reference point is invoked and it is implied that the process is prior to that reference point and, typically, "has yielded a result which obtains in the present" (Declerck, 1991:101).

While most prototypical-ee nominalizations establish a relationship of which the semantics is similar to that of clausal or adjectival (stative) passive constructions (as in (11) and (12) respectively),
detainee
(s)he is detained
employee
(s)he is employed
experimentee
(s)he is experimented on
sendee
(s)he is sent something 


$$
\begin{array}{ll}
\begin{array}{l}
\text { adoptee } \\
\text { electee }
\end{array} & \text { an adopted child } \\
\text { abusee } & \text { an elected member }
\end{array}
$$

less prototypical, agentive -ee nominalizations express meanings which are comparable to those realized by two other constructions with the past participle in English: some shift the profile to a state which the profiled agent finds itself in, thus resembling the adjectival use of intransitive verbs (see (13)); others are not relatable to a stative, adjectival equivalent but resemble the semantics of the present perfect use of the past participle (see (14)):

$$
\begin{array}{ll}
\begin{array}{l}
\text { enlistee } \\
\text { escapee }
\end{array} & \text { an enlisted soldier } \\
\text { retiree } & \text { an escaped prisoner } \\
\text { divorcee } & \text { that man is divorced } \\
\text { forgettee } & \text { (s)he has forgotten it } \\
\text { resignee } & \text { (s)he has resigned } \\
\text { returnee } & \text { (s)he has returned }
\end{array}
$$

Once it is established that it is past participle constructions which -ee nouns mirror and the past-participial semantics which they have in common, the most 'problematic' type of -ee nouns, the one designating agents, can be accounted for more naturally than in earlier syntactic or semantic approaches: like non-agentive -ee nominals, agentive -ee nominalizations profile an entity which is in some way 'downstream' or 'terminal', but then with respect to the flow of time, i.e. they basically profile the state a person is in. It is this stative nature which has led to analyses in terms of semantic 'passivity' (Bolinger, 1941), 'lack of volition' (Barker, 1998) and 'undergoerhood' (Portero Muñoz, 2003). What Barker's notion of 'episodic linking' seems to pick up on, then again, is the fact that the profiled state is typically the final state resulting from the process having been carried out.

Summarizing, the analyses of -er and -ee nominalization in Heyvaert $(2003,2006)$ offer an alternative, symbolic account of the extensions found within both nominalization systems. Importantly, the identification of the constructional and semantic resemblances between non-agentive -er nouns and the Subject-Finite unit of the clausal middle, on the one hand, and between agentive -ee and the agentive uses of the past participle, on the other, turn out to make a unifying account possible, of -er nominalization (in terms of the Subject-Finite and its semantics) as well as of -ee nominalizations (centred on the past-participial semantics). In the next section, I will have a look at corpus data of agentive -er and -ee variants of the same verb to find out if their semantics ties in with the overall, prototypical semantics of their respective systems.

\section{Agentive -ee and -er variants: a qualitative corpus analysis. Results and discussion}

Two sets of data were collected. A first set was extracted from a 56 million word subcorpus of the Bank of English, also known as the Collins COBUILD corpus. ${ }^{5}$ Of the agentive -ee nouns mentioned in Bauer (1983), Marchand (1969), Barker (1998) and Portero Muñoz (2003) (included here under (15)) only 7 turned out to be attested in the COBUILD corpus, viz. attendee, enlistee, escapee, resignee, retiree, returnee and signee.

advancee, arrivee, ascendee, attendee, deferee, dinee, embarkee, enlistee, enrollee, escapee, forgettee, offendee, pledgee, representee, relaxee, resignee, retiree, returnee, signee, sittee, standee, waitee, withstandee

Of only five of these the corpus included an -er counterpart, viz. attender, escaper, resigner, returner and signer (?retirer and ?enlister did not occur). In total, the COBUILD corpus thus yielded a set of 219 naturally occurring instances of -ee and -er variants of five verb stems (see Table 1 ).

A second set of -er nouns and their -ee counterparts was drawn from the British National or BNC corpus (accessed via Mark Davies's interface). ${ }^{6}$ In the BNC corpus I found a total of 407 instances of -ee and -er variants of the verbs attend, escape, resign, return and sign (Table 2 ).

In what follows, I present a detailed qualitative analysis of the COBUILD findings and the BNC data.

First, the corpus data reveals a clear 'division of labour' between the agentive -ee nominalizations and their -er counterparts. The large majority of agentive -ee nominalizations in the COBUILD corpus, for instance (78\% or 82 out of 105 instances), as opposed to only $12 \%$ of -er nominalizations (14 out of 114 ) turn out to designate 'someone who has V-ed (something) once and therefore finds him- or herself in the state of having V-ed'. The -er nominalizations, on the other hand, conform to the semantics of agentive -er suffixation in general and rather characterize people in terms of the dynamic

\footnotetext{
${ }^{5}$ The COBUILD corpus was accessed via remote-log in. It consists of texts from British books, ephemera, radio, newspapers, magazines (36 m words), American books, ephemera and radio ( $10 \mathrm{~m}$ words) and British transcribed speech (10 $\mathrm{m}$ words).

${ }^{6}$ The BNC (British National Corpus) corpus (100 million words) was accessed via Mark Davies' interface (http://view.byu.edu/). It contains written and spoken data from a wide range of sources from the 1970s up till 1993. The examples are reproduced here with the kind permission of Mark Davies.
} 
Table 1

An overview of the -ee nominalizations with -er variants that were found in the COBUILD corpus.

\begin{tabular}{lrr}
\hline & $-e e$ & $-e r$ \\
\hline attend & 17 & 19 \\
escape & 60 & 14 \\
resign & 1 & 1 \\
return & 24 & 60 \\
sign & 3 & 20 \\
Total & 105 & 114 \\
\hline
\end{tabular}

Table 2

An overview of the -ee nominalizations with -er variants that were found in the BNC corpus.

\begin{tabular}{lll}
\hline & $-e e$ & $-e r$ \\
\hline attend & 44 & 92 \\
escape & 45 & 35 \\
resign & 1 & 1 \\
return & 21 & 97 \\
sign & 2 & 71 \\
Total & 112 & 295 \\
\hline
\end{tabular}

meaning of ability, with either a modal or 'potential' profile (transcending actual occurrences of the process or 'having the intention of doing something') or an habitual one (based on repeated occurrences of the process).

The examples of escapee (16), resignee (17) and returnee (18) illustrate the prototypical meaning of -ee derivations:

The British Airways Boeing 757 was immediately taken out of service until a reptile expert arrived to round up the escapees. However, one slippery creature, a praying mantis, was never found. (CB)

'John Major, as Chancellor and subsequently as Prime Minister, has been responsible for economic policies which have caused a lot of hardship (...),' grumbles one resignee. (CB)

However, the real figure of returnees is unclear - many people have returned unofficially, through employment agencies. (CB)

The semantics of these -ee nouns is confirmed by the context in which they are used and which focuses on the state resulting from the nominalized process having been carried out, i.e. the fact that a reptile expert has to be called in to round up the escaped animals in (16), the dissatisfaction of the person who resigned in (17) and the final number of people who have returned in (18).

The nominalization that turns out to deviate most from this prototypical meaning of agentive -ee is attendee, all 17 of its attestations designating the state of 'being present at (a meeting, conference...)':

a. In fact, this gathering was intensely political, and the attendees would roundly applaud a series of tub-thumping speeches. (CB)

b. We recognized another parent of an autistic child and a few school personnel. The other attendees were strangers (...). (CB)

In so far as attendee designates a state which the profiled entity finds itself in, however, it fits in with central aspects of the overall semantics of the system of -ee derivation (see also Heyvaert, 2006). Significantly, moreover, the corresponding -er nominalization attender nominalizes the more dynamic sense of the underlying verb attend, viz. 'attend an institution (school, college, church), go there regularly':

a. If all this sounds a bit tame to the more adventurous night-class attender, there is plenty more on offer (...). (CB)

b. A school has cracked its truancy problem by bribing poor attenders with a McDonald's meal. (CB)

It is interesting to observe that, unlike its -ee variant, attender is typically accompanied by adjectival modifiers. They either merely serve to emphasize the regularity with which the process of attending 'going to' is carried out, as in (21), or, more often, they express a value judgement with respect to the regularity with which the process of attending takes place and carry positive or negative semantic prosody (see (20b), (22), (23) and (24)): 
The GP and his wife Donna were regular church attenders and prayers for them were said at several island services yesterday. (CB)

Counselling is the Valium of this era: whereas 30 years ago any persistent attender at the surgery was fobbed off with some pills, nowadays he (or more likely she) is sent to the counsellor (...). (CB)

(...) there did come a comment through from er a listener yesterday morning that Cyril Smith was one of the worst attenders to parliament. (CB)

Collison was a very popular member of the Upper House and, at least until ill-health overtook him, an assiduous attender.

Of the corresponding -ee nominalizations which I analysed, only one was used with adjectival modification:

Our committee consists of eleven members (...). Mostly we work by consensus but because Labour members are better attendees, we have occasionally been able to get our own way on a few matters. However, we find it's best not to push our luck too much, as the Tories are often willing to be quite critical of Government policy. (CB)

One could perhaps argue here that the NP better attendees allows for another, more '-ee-like' interpretation in which better receives a 'quality' reading and the NP better attendees is analyzed as describing the Labour members' state of being present in more detail: when they attend a meeting, they might be said to be better attendees, i.e. perform better, because they are, for instance, more attentive or better prepared. As a result of that, they may 'occasionally have been able to get their own way on certain matters'. However, the default interpretation of this instance of attendee combined with the modifier better is definitely one implying the semantics of 'regularity', which is normally associated with -er nouns.

The BNC data for attender and attendee confirms the COBUILD findings and adds further detail to our description of the discursive contexts in which both are found. A first observation concerns the discursive use of attendee. As many as 17 out of 44 attestations of the derivation figure in contexts that "count" the number of participants at a meeting, as in

a. Some 30 named attendees heard a long and detailed speech from they Mayor (...). (BNC)

b. Their list peddlers are hawking the names of 21,000 attendees, the lists with exhibitors excluded. (BNC)

c. It expects to attract $\underline{2,000}$ attendees. (BNC)

This ties in with the overall semantics of -ee. The perspective taken in these sentences is clearly 'stative', i.e. giving a stative, homogeneous snapshot of the total number of attendees attending a particular reading or exhibition. The picture emerging for attender is totally different: as in the COBUILD corpus, a large number of the BNC instances of attender (i.e. 45 out of 92) take adjectives that foreground the regularity or frequency of 'attending':

a. The Agency committee was not hostile to Buxton, except for some occasional attenders, (...). (BNC)

b. She was a faithful attender at branch meetings till she retired. (BNC)

c. (...) he was a constant attender at international conferences of the European Left. (BNC)

Consider also the following instances of attender without adjectival modification:

a. Right. Anybody wish to be put forward as conference attender? The number is limited is it? Yeah. Yeah. (BNC)

b. During the 1902 controversy the annual meeting could only muster forty attenders despite the attraction as guest speaker of W.S.Caine, Liberal Member for Camborne. (BNC)

c. One bemused attender started to shout that he could not understand the answers to such questions. (BNC)

d. The international aims of the symposia are the following: (...) To produce publications with contributions from the symposium attenders (...). (BNC)

In (28a), attender is used in a context (i.e. of a conference) in which one would expect its -ee counterpart. Still, the choice for -er appears to be motivated here by the fact that the speaker is asking for candidates, i.e. for people willing to (actively) go to the conference. In (28b), the context ('annual meeting') and the fact that numbers are given ('forty') at first sight likewise favor attendee. As in (28a), however, emphasis instead appears to be on the (active, dynamic) choice which people had to make to go to the annual meeting, as implied in the use of muster. The instances of attender in (28c and d), then, it could be argued, foreground what are basically attendees or 'people that are present at an event', but rather than depicting them in the state that they are in, they present them 'in action', as shouting, or within a broader discourse context that foregrounds their potential for acting as dynamic entities, i.e. as people that not only attend the conference but also write a contribution for the symposium proceedings. attender might thus have been favored here primarily for its active, dynamic -er semantics, rather than for its typical going to meaning. 
Of the remaining -er nominals which I investigated (escaper, returner, resigner and signer), the large majority turned out to realize typical -er meanings. Whereas escapee in (16), for instance, referred to entities that have escaped, escaper in (29a and b) designates 'someone intending to escape':

a. The third problem, Anthony said, was connected to the second and influenced it - and was fundamental to the whole matter. Where did the escaper want to go and how did he propose to travel? (CB)

b. He learned that there were highly expert forgers in the camp (...). Given time they would produce all the papers an escaper needed for his particular plan. (CB)

In (29a and b), it is the context which makes clear that escaper is to be interpreted as 'someone with the intention of escaping'. A similar meaning is found in (29c), but here the adjective prospective is added to elicit the semantics of 'potentiality':

c. The staff on the whole are very good, but I think they have to be kept informed as to prospective escapers from prison. (CB)

When there is neither a context nor an adjective to foreground the meaning of potentiality or intention with escaper, its meaning seems to come close to that of escapee, although the -er variant in that case seems to foreground especially the dynamicity and 'know how' of the profiled entity (as in (30a)) or is used when the escape attempt has been unsuccessful and has not led to the resultant state of 'being an escaped prisoner' (as in (30b)). Its counterpart escapee, on the other hand, rather emphasizes the resultant state ((31a)) and the consequences of escaping (as in (31b)).

a. Prison escaper John Hannan has set a British record by staying on the run for 42 years. (CB)

b. Jail escaper back inside. (CB)

a. Hunt for escapee. Police are hunting for a prisoner who escaped from the Numinbah Correctional Centre on the Gold Coast on Friday night. (CB)

b. Escapee in court. Raymond Stuart Clark, 21, who escaped last week while in custody in the Ipswich Magistrates Court, yesterday appeared in Brisbane Magistrates Court charged with escaping and unlawful use of a motor vehicle. (CB)

(Note that the data in general suggests that escapee is preferred in the context of the courtroom: the BNC corpus, for instance, which also contains courtroom English, gives four attestations of the criminal offence 'harbouring an escapee'.)

The focus on dynamicity and 'know how' associated with -er also seems to lie behind Barker's (1998:709) second example of escaper, designating 'players on the internet go server who deliberately pretend to lose their net connection in order to avoid losing a game of go'. Yet another discourse context in which escaper seems to be favored is that in which focus is on the (dynamic) process of escaping, while it is going on, witness the BNC examples in (32):

a. They both were astonished that so far no indication of trouble had come from the town common; but reckoned that it would not be long now before it did, for a few escapers from the castle had been glimpsed running in that direction. (BNC)

b. There, and among the rows of vines, the escapers remained hidden, not knowing what to do next (...). (BNC)

c. It is said that tunnels once used by escapers from the castle still exist beneath the grounds. (BNC)

Interestingly, the semantics of 'resultant state' which appears to be characteristic of escapee can be further emphasized through the use of adjectival modifiers, as in (33):

However, there have been successful escapees from Eastenders (...). (CB)

Note, however, that some instances of escapee do seem to express -er-like meanings:

(34) a. She was light and quick. Even her speaking voice had a musical sound - and Mother never laughed more than when Liddie was working by her side. Daddy called Liddie 'the escapee', but it seemed to Nina he must have called her this before she left too, that he was talking about some quality Liddie had - had always had - of belonging more to the world out there than to their family. (CB)

b. What are the locks for $<$ F02 $>$ er locks on the windows Because he escapes $<$ F01 $>$ Right. What $<$ ZF1 $>$ just $<\mathrm{ZFO}>$ just go off $<$ F02 $>$ He's an escapee. (CB ${ }^{7}$

\footnotetext{
${ }^{7}$ The codes which you find in between angle brackets are codes inserted in the spoken corpora of the Bank of English. $<$ ZF1 $>$ and $<$ ZF0 $>$ are used to enclose accidental, exact repetitions involving whole or part words or phrases. $<$ F01 $>$ and $<$ F02 $>$ signal turn-taking.
} 
The nominalization escapee in (34a) is used to describe a person that has eventually managed to escape (cf. before she left too), but the context also makes clear that the noun is meant to identify Liddie as 'someone who could/had the ability of escaping', i.e. of 'belonging more to the world out there than to their family'. And this is a meaning one would expect to see expressed by an -er nominal.

In short, escapee and escaper in general seem to be used with distinct meanings, which can be further foregrounded in the context or by means of adjectival modification. Unlike with attendee and attender, however, adjectival modification is rare and certain contexts appear to allow for both the -ee semantics (with its emphasis on the resultant state the designated entity is in) and that of -er derivation (with its focus on dynamicity and ability):

MPs speculated last night that Mr Baker's head would be on the block if the latest bombers turned out to be the two IRA escapers. (CB)

The formations resigner and returner turn out to largely fit the semantic schema of -er nouns in general. Resigner in (36) designates 'someone who has the habit of resigning, who easily resigns' rather than 'someone who has resigned' (perhaps even with passive connotations as in 'someone who has been forced to resign'), as did resignee in (17) (repeated below). Note that resigner would also have had that meaning in the absence of frequent (a comment also made by Lemmens (1998:156) about seller, which, like bestseller, implies that an item 'sells well'). Resigner thus resembles -er nouns like gambler and drinker which designate a persistent habit.

'John Major, as Chancellor and subsequently as Prime Minister, has been responsible for economic policies which have caused a lot of hardship (...),' grumbles one resignee. (CB)

I am not a frequent resigner. I usually accept the American adage 'if you don't keep your feet under the table, you don't get to carve the turkey'. (CB)

The -er formation returners in (37a) designates 'someone who (is willing to) return(s) to work'. Interestingly, also when it is based on the transitive subsense of 'returning a ball', returner ties in with the overall semantics of -er and expresses ability (see (36b)) ('someone who is able to return the ball well'):

a. Women returners aged 25-44 would be the largest single group joining the workforce, they predicted. (CB)

b. A few dozen people gathered around a practice court at the US Tennis Centre gasped as the young Australian fired aces and winners past a man many consider the best returner in the business. (CB)

With returners we find adjectival modification that picks up on either the ability expressed by it (in those cases where returner is a sports term, as in (37b)), or on the regularity that is implied in it (as in (37c)):

c. (...) to Pilgrim Hospital Medical Library, especially Shirley Brewster, for making available books and articles, and putting up with a chronic late returner. (CB)

At first sight, the use of regular with returnees in (38) seems odd. However, as with better attendees in (25), this example seems to allow for two readings: one which considers it as synonymous with returners (in which case the adjective regular foregrounds the implied regularity), and one which is more -ee-like and emphasizes that the people in (38) 'have since regularly enjoyed the state of having returned to San Francisco'.

Maureen and I, and our (at that time) very young children, lived in San Francisco for most of 1984-85 and we've been regular returnees ever since. (CB)

I also found an example in which the adjective potential modifies returnees (see (39)). Again, this adjective in my view might be analyzed as modifying the 'state of having returned', resulting in the reading 'people that might find themselves in the state of having returned' (cp. also with (40), in which agentive retiree combines with potential to profile 'people that may soon find themselves in the state of being retired'):

The obstacles facing potential returnees are numerous. (CB)

Instead of paying fund managers fees to produce mediocre or negative returns, many potential retirees instead are opting to try their own hand at investment markets. (CB)

The BNC data for returnee add to this that returnee is typically used to designate 'groups of people' (only 2 out of 21 attestations refer to an individual returnee), in the context of migration:

$$
\text { (...) it could certainly absorb more than 100,000 Palestinian returnees. (BNC) }
$$

Finally, the distinction between signer and signee appears to be motivated as well: while signees is used in contexts where the emphasis is on the contractual state resulting from signing a contract or treaty (see (42) and (43)), its -er counterpart signers 
is used to designate 'someone able to sign, i.e. use sign language' (as in (44)), in the context of bank accounts (as in (45)), designating 'someone with the potential/permission of signing', or it is used as an 'ad hoc' -er noun with temporal semantics in the context of pamphlets and petitions, where the focus is not so much on the state which the signers find themselves as on their dynamic involvement in the process of signing (see (46a and b)). Note that in (42), signees can have both a passive and an active reading, i.e. it can denote someone who has signed for the Superleague or someone who was signed by the Superleague. In either case, however, the -ee derivation emphasizes that the person that (was) signed now finds him- or herself in the state of 'having (been) signed', with all the contractual obligations and rights that go with it.

Arthurson, who had previously announced a blanket ban on representative honours for superleague signees, said selectors were yet to be given guidelines on who they could name. (CB)

SOVIET TREATY SIGNEES. President Gorbachev's spokesman says the first of the republics to sign the new Treaty of Union - which gives republics much greater power - will do so in two weeks' time. (CB)

He was a hearing son of deaf parents, and therefore a fluent signer. (BNC)

If you purchase with a co-signer, be certain to apply for financing and hold title as individuals. (CB)

a. In a one-sentence letter to Mr. Clinton, 184 members (...) wrote: "We urge you not to send ground troops to Bosnia." The list of signers is 34 members short of the majority needed to defeat a resolution expected next week supporting the troop deployment. (CB)

b. "Do the American People Want War?" asked a full-page advertisement in the New Republic that appeared early in March 1917. Its signers were three left-wing progressives - Amos Pinchot, Randolph Bourne, and Winthrop Lane - and the socialist Max Eastman. (CB)

\section{Conclusion}

In this paper I have zoomed in on deverbal nominalization pairs such as escapee-escaper, attendee-attender which are agentive and based on the same verb form. The semantic differences between variants like these have always been minimized or treated as idiosyncratic and their link with the semantics of the systems of nominalization which they belong to is unclear. In an attempt to find out whether the nominalizations that belong to such pairs constitute interchangeable, synonymous structures or rather represent motivated instantiations of their respective nominalization systems, I searched the COBUILD and the BNC corpus. I collected a set of 219 -er and -ee nouns in the former and 407 in the latter corpus (attendee-attender, escapee-escaper, resignee-resiger, returnee-returner, signee-signer) and checked the meanings of these empirical examples against the semantics of their overall systems, as identified in Heyvaert (2003) for -er nominalization and in Heyvaert (2006) for -ee derivation.

It was found that in a majority of cases, the -ee and -er variants are not synonymous, but semantically distinct, straightforward instantiations of the constructional semantics of their respective systems of nominalization. Interestingly, some -ee and -er variants were shown to nominalize distinct subsenses of their base verb, with -ee attaching to those subsenses implying a state or pointing to the consequences of carrying out the process and -er nominalizing those meanings that imply ability or a more dynamic involvement in the process. Attendee, for instance, was shown to nominalize the stative meaning 'be present at', whereas attender nominalizes the more dynamic meaning of 'going somewhere regularly'. Likewise, returnee designates the state resulting from the intransitive process of 'going back somewhere' while returner is often used in the dynamic ability sense of 'being able to return a ball in a game of tennis or football'. And, finally, the nominalization signee turns out to typically relate to the meaning of 'signing a contract' (with its emphasis on the obligations and rights that are attached to contracts), whereas signer nominalizes the meaning of 'signing a document to indicate that you agree with what is written' or 'use sign language to communicate'.

Through the analysis of contextualized, attested examples of -ee and -er nominalizations, it was also revealed that the wider discourse context contributes significantly to the interpretation of nominalizations: the discourse context often confirms and elaborates on what is being profiled by the nominalization - the state the profiled entity finds itself in, or rather a habit, ability or intention which it has. Some nominalizations (like attenders and returnees/returners) turn out to make frequent use of adjectival modification to foreground certain meanings and/or express a value judgement about them (cf. attenders).

The comparison of agentive -ee and -er nouns based on the same lexical verb thus makes clear that the analysis of deverbal nominalizations has to include the lexical semantics of the base verb (with its various subsenses), the discourse context in which the nominal is used and the lexicogrammatical properties of the noun phrase in which it occurs, with the adjectival modifiers that function in it. Importantly, my analysis also shows that even derivations which at first sight appear to be idiosyncratic results of semantic specialization tend to instantiate the semantics of the system they belong to. True synonymy or interchangeability remains rare among derivations.

\section{References}

Barker, Chris, 1998. Episodic -ee in English: a thematic role constraint on new word formation. Language 74 (4), 695-727. Bauer, Laurie, 1983. English Word-Formation. Cambridge University Press, Cambridge. 
Bengtsson, Elna, 1927. Passive Nouns with a Concrete Sense in English. Häkan Ohlsson, Lund.

Bolinger, Dwight L., 1941. Among the new words. American Speech 16, 91-92.

Booij, Geert, 1986. Form and meaning in morphology: the case of Dutch 'agent nouns'. Linguistics 24, $503-517$.

Booij, Geert, Lieber, Rochelle, 2004. On the paradigmatic nature of affixal semantics in English and Dutch. Linguistics 42 (2), $327-357$.

Davidse, Kristin, Heyvaert, Liesbet, 2007. On the middle voice: an interpersonal analysis of the English middle. Linguistics 45 (1), $37-82$.

Declerck, Renaat, 1991. A Comprehensive Descriptive Grammar of English. Kaitakusha, Tokyo.

Fellbaum, Christiane, 1986. On the Middle Construction in English. Indiana University Linguistics Club, Indiana.

Heyvaert, Liesbet, 1997. Patientive -er nominals. Leuven Contributions in Linguistics and Philology 86 (4), 433-456.

Heyvaert, Liesbet, 2003. A Cognitive-Functional Approach to Nominalization in English. Mouton, Berlin/New York.

Heyvaert, Liesbet, 2006. A symbolic approach to deverbal -ee derivation. Cognitive Linguistics 17 (3), $337-364$.

Jespersen, Otto, 1914-1929. A Modern English Grammar on Historical Principles, 7 vols.. George Allen and Unwin, London.

Kastovsky, Dieter, 1971. The old English suffix -er(e), Anglia. Zeitschrift für Englische Philologie 89, 285-325.

Kastovsky, Dieter, 1986. Diachronic word-formation in a functional perspective. In: Kastovsky, D., Szwedek, A. (Eds.), Linguistics Across Historical and Geographical Boundaries. In Honour of Jacek Fisiak on the Occasion of His Fiftieth Birthday, vol. 1: Linguistic Theory and Historical Linguistics. Mouton, Berlin/New York, pp. 409-421.

Keyser, Steven J., Roeper, Thomas, 1984. On the middle and ergative constructions in English. Linguistic Inquiry 15, $381-416$.

Langacker, Ronald W., 1982. Space grammar, analysability, and the English passive. Language 58 (1), $22-80$.

Langacker, Ronald W., 1991. Foundations of Cognitive Grammar. Descriptive Application. Stanford University Press, Stanford.

Lemmens, Maarten, 1998. Lexical Perspectives on Transitivity and Ergativity. Causative Constructions in English. John Benjamins, Amsterdam/Philadelphia.

Levin, Beth, Rappaport, Malka, 1988. Nonevent -er nominals: a probe into argument structure. Linguistics 26, 1067-1083.

Marchand, Hans, 1969. The Categories and Types of Present-day English Word-Formation. C.H. Beck, Munich.

Portero Muñoz, Carmen, 2003. Deverbal nominalizations in -ee: a Role and Reference Grammar based semantic analysis. English Language and Linguistics 7 (1), 129-159.

Rappaport Hovav, Malka, Levin, Beth, 1992. -ER nominals: implications for the theory of argument structure. In: Stowell, T., Wehrli, E. (Eds.), Syntax and Semantics, vol. 26: Syntax and the Lexicon. Academic Press, New York, pp. 127-153.

Ryder, Mary E., 1991. Mixers, mufflers and mousers: the extending of the -er suffix as a case of prototype reanalysis. In: Proceedings of the Berkeley Linguistics Society, vol. 17. pp. 299-311.

Ryder, Mary E., 1999. Bankers and blue-chippers: an account of -er formations in present-day English. English Language and Linguistics 3 (2), 269-297.

Taeldeman, Johan, 1990. Afleidingen op -sel: semantiek, produktiviteit en integratie in een globale verantwoording van deverbatieve nomina. In: De Caluwe, J. (Ed.), Betekenis en produktiviteit. Gentse bijdragen tot de studie van de Nederlandse woordvorming. Studia Germanica Gandensia, Gent, pp. 77-115.

Liesbet Heyvaert is assistant professor in English Linguistics at the Department of Linguistics, University of Leuven (Belgium). She has published mainly on nominalization and middle formation and is the author of $A$ cognitive-functional approach to nominalization in English (2003, Mouton). 